\title{
Economic evaluation of care for the chronically ill
}

\author{
A literature review
}

ROBBERT HUIJSMAN *

\begin{abstract}
Financial problems of governments and the consequent urge to set limits on health care growth have increased the importance of economic rationalization. A systematic review of the present body of knowledge might facilitate the need to set priorities in health care policies and research in an ageing society with growing numbers of the elderly and chronically ill. After explaining the purpose and methods of full economic evaluation, we review the literature on 3 major chronic diseases, diabetes mellitus (20 publications), rheumatoid arthritis (15) and chronic obstructive pulmonary disease (COPD) and asthma (8). This review serves 2 objectives: to review the existing literature and to assess its quality. The review reveals a ladk of full economic evaluation in this sector of health care. The total number of references to the specffied chronic diseases covers $5 \%$ of all economic literature and $44 \%$ of all references under Index Medicus' heading 'economics', while the burden of illness is substantial, resulting in high indirect costs to the patients themselves and to society. The dominant approach is cost-effectiveness analysis (71\%), followed by cost-benefit analysis (20\%). Cost-utility analysis is rare (9\%), partly because it is still in the phase of development. However, this approach can deal better with the objectives of many interventions in chronic care, i.e. increasing the quality rather than the quantity of life. We make a plea for full economic evaluation of chronic care programmes and for the development of quality of life measures which cover the broad domain of well-being of the chronically ill.
\end{abstract}

Key words: chronic diseases, diabetes mellitus, rheumatoid arthritis, chronic obstructive pulmonary disease and asthma, full economic evaluation, quality of life

W

ith ageing populations and the strong relation between prevalences of chronic diseases and age, there will be increasing numbers of people with chronic diseases, of which many depend on the provision of health care. In this article, we adhere to the viewpoint that in ageing societies the burden of illness which comes with chronic diseases is a relevant starting point for establishing priorities for health care programmes and economic evaluation (besides the traditional focus on interventions), thus adopting the measurement iterative model of Tugwell et al. ${ }^{1}$ from quantifying the burden of illness, through aetiology to validating interventions and their evaluation. Others have addressed the demographic and epidemiological trends, which we need to discuss briefly in order to substantiate our viewpoint and to gain more insight into the effects of an ageing society. At first glance, there seems to be little information from the literature that could be used to support policy choices based on economic (other than, for instance, societal or ethical) considerations of the costs and outcomes of alternative health care programmes in the complex area of care for the chronically ill. Figures of the use of care resources are difficult to provide and there have been few attempts to analyse economically programmes particularly targeted at

Correspondenca: R. Huljman, Ph.D. Institute for Health Care Polky a Management, Erasmus University Rottedam, PO B-ox 1738, 3000 DR Rotterdam, The Netherlands, tel. +31 $104088525 / 32$, fax +31104522511 the elderly and chronically ill. Therefore, after explaining the purposes and methods of full economic evaluation, we review the literature on full economic evaluation of care for the chronically ill. This review serves 2 objectives: to review the existing literature and to assess its quality.

SELECTION OF EMPIRICAL FIELD: 3 CHRONIC DISEASES Practical limitations made us carefully select 3 major chronic diseases, serving as a kind of case study for the total field of chronic diseases. We selected diabetes mellitus (DM), rheumatoid arthritis (RA), and chronic obstructive pulmonary disease (COPD) and asthma. These chronic diseases have been chosen for several reasons: a) in The Nerherlands they rank among the top 10 diseases and causes of death in the general population ${ }^{2}$, b) they cause a severe burden of illness for both the individual patient and society and c) their prevalence rates are highly related to age (table 1), which is of great importance to an ageing sociery.

\section{SOME RELEVANT TRENDS AND THEIR IMPACT ON THE CARE SECTOR}

With variation between countries, the demographic trend is unmistakeably towards a larger population of the (very) old. In Western Europe, the number of elderly above 65 years is higher in Denmark, Belgium, Eastern Germany and the UK (almost 16\%) than in The Netherlands (13\%). ${ }^{3}$ A similar picture can be seen for the percentage 
of 85 years and over. Double-ageing, i.e. an increasing share of the very old within the population of elderly, is concentrated in females. Predictions on the furure situation in the Dutch population show an increasing share of the elderly in the total population, to up to $24 \%$ by the year $2040 .{ }^{4}$ Simple extrapolation for the year 2000 , combining demographic trends with age-specific care consumption rates have shown that The Netherlands will experience a yearly increase in patients of approximately $2 \%,{ }^{5,6}$ By the turn of the century, total expenditure will increase by 20-25\% in real terms. The share of the elderly within the client populations of health care services, which in The Netherlands was on average already $40 \%$ in 1990 , will rise further. ${ }^{4}$

Such extrapolations are unsatisfactory for a number of reasons. First, one may expect age-specific demands to shift over time. Subsequent cohorts do not just get older, but their health status also improves over time, due to changing health habits and attitudes and more effective prevention and curative programmes. This may lead to a concentration of illness in the last years of life, but it may also cause longer periods of illness, albeit at later stages in life. Many doubt whether the age-specific prevalences of a number of important chronic diseases (table 1) will change significantly in the coming years. Nevertheless, when age-specific prevalences remain more or less stable, the double-ageing of the population and the strong relation between prevalences and age, will inevitably result in increasing numbers of chronically ill.

It is not only the prevalence but also the intensity of health care consumption which increases with age. Thus, the average cost per year per person is substantially higher in older than in younger age groups (table 2). ${ }^{7}$ For women in the highest age brackets the figures are even $30 \%$ higher. Mental disorders are the most expensive disease category, accounting for $20 \%$ of all health care costs and $30 \%$ of all traceable diagnosis-related costs. For the elderly of 80 years and over the average cost related to dementia accounts for $18 \%$ of all costs. The costs related to dementia will double towards the year 2030. Also, the costs of some of the chronic diseases which we focus on in this article belong to the group of diseases with the sharpest increases in costs during the decades to come. Setting the
Table 2 Average costs per capita for chronic diseases in The Netherlands, 1988 (in Dfl)

\begin{tabular}{|c|c|c|c|c|c|c|}
\hline & \multicolumn{5}{|c|}{ Age (years) } & \multirow[b]{2}{*}{ Total } \\
\hline & $0-19$ & $20-44$ & $45-64$ & $65-79$ & $\geq 80$ & \\
\hline $\begin{array}{l}\text { COPD and } \\
\text { asthma }\end{array}$ & 13 & 7 & 37 & 124 & 163 & 31 \\
\hline Diabetes mellıtus & 3 & 6 & 32 & 134 & 248 & 30 \\
\hline $\begin{array}{l}\text { Rheumatoid } \\
\text { arthritis }\end{array}$ & 1 & 2 & 14 & 46 & 87 & 11 \\
\hline Mental disorders & 210 & 615 & 550 & 847 & 3297 & 592 \\
\hline Other diseases & 677 & 830 & 1,325 & 3,519 & 7,865 & 1,350 \\
\hline Non-traceable & 428 & 534 & 790 & 1,290 & 2,194 & 679 \\
\hline $\begin{array}{l}\text { Total costs per } \\
\text { capita }\end{array}$ & 1,332 & 1,994 & 2,748 & 5,9601 & 13,854 & 2,693 \\
\hline
\end{tabular}

Source: reference 7

cost level of 1988 at 100 , the index of average health care costs in The Netherlands will be 139 in 2030 . The indices for rheuma and diabetes mellitus will rise to above $170 .{ }^{7}$ Another departure from the simple extrapolation arises from the fact that technology in the area of service delivery for the elderly and chronically ill may also progress. There is considerable scope for the introduction of (new) technologies which may help people to stay independent and postpone the use of institutional care. ${ }^{8}$ However, taking technological development in the 'cure' sector as an example, it is not self-evident that technological change will make the production of services less expensive because it is often aimed at increasing the effectiveness of interventions rather than saving costs.

\section{ECONOMIC APPRAISAL}

\section{Relevance}

The trends we described above, result in a growing gap between the demand for services and the resources available from the public budget to finance these demands. One of the options to bridge this gap is to increase the efficiency of public spending and health care policy, in which economic appraisal is playing an increasing role. Some countries, such as Australia and Canada, already use economic appraisal as an integrated part of their decisions on the reimbursement of new pharmaceutical products. In most developed countries major decisions on, for instance, the initiation of screening programmes are not taken without consideration of their cost-effectiveness profiles. These initiatives concentrate on the cure sector; policy decisions within the care sector seem to lack an economic foundation. Until now, the costs of most services have not been evaluated and the outcomes of most care provisions have not been measured. ${ }^{9}$ There- 


\begin{tabular}{|c|c|c|c|c|c|c|}
\hline & & \multicolumn{5}{|c|}{ Are both inputs and outputs of the alternatives examined? } \\
\hline & & \multicolumn{3}{|c|}{ No } & \multirow{2}{*}{\multicolumn{2}{|c|}{$\begin{array}{c}\text { Yes } \\
\text { Examines both unputs and outputs }\end{array}$}} \\
\hline & & Examines only the out & tputs & s only inputs/costs & & \\
\hline & & $1 \mathrm{~A}$ & Partial evaluation & 1B & 2 & Partial evaluation \\
\hline & No & Outcome description & & Cost description & & Cost-outcome description \\
\hline \multirow[t]{2}{*}{$\begin{array}{l}\text { Comparison of } \\
\geq 2 \text { altematives? }\end{array}$} & & $3 \mathbf{A}$ & Partial evaluatıon & $3 B$ & 4 & Full economic evaluation \\
\hline & Yes & Efficiency or efficacy e & evaluation & Cost analysis & & Cost-minimızation, CEA, CBA, CUA \\
\hline
\end{tabular}

Figure Different forms of economic appraisal

fore, a review of the literature on economic analysis of care for the elderly and chronically ill may be useful.

\section{Different methods}

Only those studies which make a simultaneous comparison between alternative strategies and where both the costs and outcomes are being considered, are seen as full economic evaluations (figure). Drummond et al. ${ }^{10}$ define full economic evaluation as "the comparative analysis of alternative courses of action in both their costs and consequences". This definition rules out other forms of research, such as randomized clinical trials or efficacy evaluations (which assess only the outcomes of clinical strategies) and cost analysis and cost of illness studies (which exclude the outputs of programmes). These forms of partial economic evaluation often result in estimated cost per (treated) patient and can be useful if the effectiveness of alternative strategies has been well established or does not differ between altematives.

In comparing costs and consequences of alternative programmes, there are 4 basic types of full economic evaluation: cost-minimization analysis, cost-effectiveness analysis, cost-benefit analysis and cost-utility analysis. ${ }^{10}$ Cost-minimization is a comparative approach to identify the least expensive provision from a set of alternatives with the same outcome. Results are often reported in terms of cost per treated patient, although this is a measure of output rather than outcome. Often, delicate and subjective judgement is necessary to discriminate cost analyses from cost-minimization. Therefore, we decided to exclude this type of analysis from our review.

Cost-effectiveness analysis (CEA) is a method in which costs and consequences of some provisions are compared with their best alternatives. Costs are valued in money, while effects are measured in some natural unity. The unit of effect depends on the programmes that are being compared and may take the form of a cost per life saved or per saved life year or levels of function or proportion of patients in whom symptoms are controlled. Since the ultimate aim of health care programmes is to prevent morbidity and mortality, years of life gained are typically used as the unit of effect. ${ }^{11}$ In cost-benefit analysis (CBA), all costs and benefits, including the gains in health, are valued in monetary terms and the results are usually reported as a net cost or benefit. Although some authors argue that $\mathrm{CBA}$ can also be applied to one single strategy, we rule that out as it is not a full economic evaluation according to Drummond et al.'s definition. ${ }^{10}$ Cost-utility analysis (CUA) can be seen as an extension of cost-effectiveness analysis in the sense that changes in the quality of life are taken into account. The result of a CUA is usually a cost per quality adjusted life year (QALY) gained. QALYs combine quantity and quality of life into one single index which allows comparisons across programmes. Although this type of analysis has the advantage of combining effects that programmes can have on different outcomes by valuing the change in each outcome, the analyst is faced with many problems, such as weighing different dimensions into one inde ${ }^{1}$ and valuing human life and suffering. ${ }^{11}$ The result is an ongoing debate ${ }^{12}$ and the development of alternative measures for CUA, for instance 'healthy years equivalent'. ${ }^{13,14}$ As the measurement of these concepts have been pursued in very different ways, it seems too early to recommend standardization. 15

Methodology of full economic evaluation: a check list Because full economic evaluation is a rather extensive form of research, a check list is helpful. We used the check list of Drummond et al., containing 10 questions to be considered when assessing the appropriateness of the methodology employed in a study (table 3). ${ }^{10,15}$

The first question, concerning the alternatives being compared and the viewpoint(s) underlying the comparison, is very general and relevant to all scientific efforts. ${ }^{10}$ A comprehensive description of the competing alternatives (question 2) and substantiated evidence of the effectiveness of these options (question 3) enables the reader to judge the usefulness, applicability and comparability of the programmes and to assess the completeness of the study. Sometimes, analysts either explicitly or implicitly choose the current programme as an alternative ('doing nothing') to the new strategy, but we feel that this choice should be substantiated in detail. The perspective of the study has to be clearly identified because of the consequences for the selection of relevant costs and outcomes (question 4). Most authors recommend the societal perspective in which all direct and indirect costs, within and outside the health care sector, are included.15,16 Sometimes, a narrower perspective can be adopted, for instance, the viewpoint of a third-party payer, a care provider or the consumer. Each of these alternatives is more limited than the societal perspective and the consequent resource allocations may be suboptimal from the 
societal point of view. However, this is the very nature of decentralized decision making. All relevant costs and outcomes of all relevant alternatives have to be included in the analysis (question 5) and valued sensibly (question 6). This often raises problems, because the real costs are sometimes unknown. Economists are reluctant to use tariffs or charges in economic evaluation, because these are negotiated over between health care providers and third-party payers and usually do not represent real costs. In practice it can be very difficult and costly to reveal the actual costs, so we adopt a pragmatic approach in this matter. The stream of costs and outcomes have to be discounted over time (question 7), because different programmes generally have different time profiles of costs and/or consequences, but must be compared at one point in time (usually the present). In this way we eliminate the consequences of time preference, i.e. the phenomenon that individuals and society prefer money or resources now instead of later because of the benefits in the interim, even in a world without inflation and bank rates. ${ }^{10}$ The social rate of time preference is a measure of society's willingness to forgo consumption (gratification) today in order to have a greater consumption (gratification) tomorrow. Although there remains some debate, the most commonly used rate at present is $5 \%$ per year. ${ }^{15}$ In the early 1980s, this choice lacked serious empirical backing, ${ }^{17}$ but a study of short- and long-term interest rates in 9 countries came up with supportive evidence to fix the discount rate at $5 \% .{ }^{18}$ Another point of discussion concerns the discounting of health effects, ${ }^{19}$ for which some authors advocate lower interest rates, ${ }^{20}$ but there seems to be no solid ground to justify a specific regimen of time preference. $^{18}$

Another important foundation of economic evaluation is the concept of marginal analysis (question 8 ). In order to make the proper allocation decisions for scarce resources, it is necessary to examine additional or marginal effects of additional or marginal increases in resource expenditure.

Table $3 \mathrm{~A}$ check list for assessing economic evaluations in health care

1 Was a well-defined question posed in an answerable form?

2 Was a comprehensive description of the competing altematives given?

3 Was there evidence that the programme's effectiveness had been established? How strong was the evidence (through a randomized, contolled clinical trial)?

4 Were all important and relevant costs and consequences for each alternative identified?

5 Were costs and consequences measured accurately in appropnate physical units?

6 Were costs and consequences valued credibly?

7 Were costs and consequences adjusted for differential timing? (discounting)

8 Was an incremental analysis of the costs and consequences of altematives performed?

9 Was a sensitivity analysis performed?

10 Did presentation and discussion include all of the issues that are of concern to users?

Source: reference 15
Sensitivity analysis should also show the influence of various discount rates on the results of the study (question 9). In general, sensitivity analysis is used to assess the robustness of the assumptions underlying the study and of the qualitative conclusions and to identify areas for further research on those variables which are crucial to the results. The last question of the check list is crystal clear, but quite often researchers 'forget' to address, for instance, the distributional, legal and ethical issues relevant to the (introduction of the) programme. Finally, the analyst should be as explicit as possible about the various methodological, technical and value judgements he or she has made carrying out the study. ${ }^{10}$

\section{REVIEW OF THE LITERATURE}

\section{Selection methods}

We used MEDLINE (1984-1993) on CD-ROM to find publications on the 3 chronic diseases. Search procedures in CD-ROM make use of the medical subject headings of the Index Medicus, which are based on both the title and the contents of a publication. We selected all references, including full economic evaluations, on diaberes mellitus (with 8 medical subject headings: diabetes mellitus, ketoacidosis, angiopathies, coma, diet, nephropathies, neuroparhies and retinopathy), rheumatoid arthritis (with 3 headings: arthritis-rheumatoid, osteoarthritis and osteomyelitis) and chronic obstructive pulmonary diseases, including asthma (with 'lung-disease-obstructive' as the heading). This sample of publications was completed, using the Economic Evaluation Bibliography of approximately 1,900 publications, ranging from journal articles and editorials to discussion and research papers. ${ }^{21}$ According to the authors, this bibliography covers almost $100 \%$ of the English language references over the period 1964-1992. For COPD and asthma, this article is also based on a recent review. ${ }^{22}$ Drummond et al.'s definition ${ }^{10}$ was used to classify an economic study as a full economic evaluation. Finally, to judge the rigour of an economic evaluation, we used the check list, as explained above.

\section{General results}

Table 4 presents the stream of publications for the 3 chronic diseases during the period 1984-1993. The average number of publications varies from 2,100 to 2,780 papers per year, of which $0.3 \%$ fits the Index Medicus' subject heading 'economics'. Although this heading is broad, it provides us with adequate access to the full economic evaluation literature.

The biblography contains 1,887 publications of which $56 \%$ are not on full economic evaluations: $18 \%$ have been classified as cost analysis studies (including cost of illness studies), $21 \%$ as review articles and methodological papers and $17 \%$ as other papers, including comments and letters to the editor(s). For all diseases together, CEA is the most commonly used method (31\%), followed by CBA (10\%) and CUA (3\%). The latter is a new but rapidly growing area of work, although the quality of technical execution is still poor and the concept of utility itself is debated upon, as mentioned above. ${ }^{15,23}$ 
One-fifth of all economic studies are concerned with diseases of the circulatory system and $13 \%$ focused on infectious and parasitic diseases. Mental disorders have been studied in $5 \%$ of all publications. The bulk, however, is classified into the category of others, also including the 3 chronic diseases central to this paper. The most important type of interventions described are drugs (22\%), therapy $(26 \%)$ and prevention (17\%). Alternatives in health service organization or location of care have been studied less frequently $(13 \%) .^{21}$

These general figures raise the suspicion that chronic care is lacking attention from economists. Table 5 further demonstrates this caveat. In total, the references to the 3 chronic diseases cover only $5 \%$ of all economic literature. Relatively more attention has been paid to cost (-minimization) analysis, particularly cost of illness studies, but we did not classify these as full economic studies. Full economic evaluation studies into chronic diseases and the elderly have been performed as often as in other health care fields, accounting for approximately $45 \%$ of all references in the economic literature. Other economic, especially cost of illness, studies may serve to clarify the economic significance of disease-specific intervention. If any publication has been used in that way, it will be stated clearly.

Table 4 Number of publications for the 3 selected chronic diseases, 1984-1993. All economic references, including full economic evaluation are in parentheses

\begin{tabular}{lcccccc}
\hline $\begin{array}{l}\text { Year of } \\
\text { publication }\end{array}$ & \multicolumn{2}{c}{$\begin{array}{c}\text { COPD and } \\
\text { asthma }\end{array}$} & \multicolumn{2}{c}{$\begin{array}{c}\text { Diabetes } \\
\text { mellitus }\end{array}$} & \multicolumn{2}{c}{$\begin{array}{c}\text { Rheumatold } \\
\text { arthritis }\end{array}$} \\
\hline 1984 & 2,448 & $(6)$ & 1,954 & $(3)$ & 2,627 & $(10)$ \\
1985 & 2,557 & $(3)$ & 2,181 & $(-)$ & 2,752 & $(8)$ \\
1986 & 2,783 & $(5)$ & 2,267 & $(-)$ & 2,912 & $(10)$ \\
1987 & 2,672 & $(5)$ & 2,368 & $(2)$ & 2,920 & $(2)$ \\
1988 & 2,704 & $(9)$ & 2,559 & $(3)$ & 3,063 & $(9)$ \\
1989 & 2,887 & $(9)$ & 2,581 & $(7)$ & 3,031 & $(7)$ \\
1990 & 3,006 & $(4)$ & 2,803 & $(8)$ & 3,060 & $(8)$ \\
1991 & 2,785 & $(9)$ & 2,906 & $(13)$ & 2,938 & $(4)$ \\
1992 & 1,905 & $(4)$ & 1,864 & $(9)$ & 1,969 & $(2)$ \\
1993 & 2,527 & $(10)$ & 1,545 & $(20)$ & 2,552 & $(7)$ \\
& & & & & & \\
Total number & 26,274 & $(64)$ & 23,028 & $(65)$ & 27,824 & $(67)$ \\
\hline
\end{tabular}

Source: Medline

Table 5 Full economic evaluation references for selected chronic diseases

\begin{tabular}{|c|c|c|c|c|}
\hline Type of study & $\begin{array}{l}\text { COPD and } \\
\text { asthma }^{2}\end{array}$ & $\begin{array}{c}\text { Drabetes } \\
\text { mellitus }\end{array}$ & $\begin{array}{c}\text { Rheumatoid } \\
\text { arthritis }\end{array}$ & $\begin{array}{l}\text { All sturdies } \\
(\%)\end{array}$ \\
\hline CEA & 15 & 11 & 5 & $580 \quad(70)$ \\
\hline CBA & 4 & 3 & 1 & $191 \quad(23)$ \\
\hline CUA & 1 & 1 & 2 & $56 \quad(7)$ \\
\hline Total number & 20 & 15 & 8 & $827(100)$ \\
\hline $\begin{array}{l}\text { Of which in } \\
\text { Backhouse }^{21}\end{array}$ & 12 & 14 & 8 & \\
\hline
\end{tabular}

\section{Methodological rigout}

The last line of table 5 shows that the completeness of the bibliography is (almost) perfect for theumatoid arthritis and diabetes mellitus, but far less satisfying for COPD and asthma. Our review research resulted in 8 more studies than found by Backhouse et al. ${ }^{21}$ We used the same sources, so to us the reason remains unclear, other than our special interest in this topic. Some references (author names) in the bibliography were spelt incorrectly.

Table 6 summarizes our efforts to address the methodological rigourness of the full economic evaluations. In each field of chronic diseases a small number of articles could not be assessed in this way, because they have been published as abstracts only. The methodological quality varies greatly, although in most cases there is a good research question and evidence of the effectiveness of a particular programme. The relevant alternatives and the identification of all costs and outcomes are not always spelt out in much detail. Greater caveats are observed with respect to discounting, incremental analysis (though this is irrelevant when a study is based on a randomized trial) and sensitivity analysis. The accuracy by which costs have been measured and valued is often unclear and not explained in sufficient detail. Overall, studies into the 3 diseases do not differ from each other when assessed against Drummond et al.'s check list. ${ }^{10,15}$

\section{THE ECONOMIC LITERATURE ON SELECTED CHRONIC DISEASES \\ Diabetes mellitus}

The estimates for the prevalence of diabetes mellitus (DM) vary from 1 to $2 \%,{ }^{24,25}$ but approximately $50 \%$ of the non-insulin-dependent diabetes mellitus (NIDDM) remains undiagnosed. ${ }^{26,27}$ The most common complications associated with DM are impaired vision, cardiovas-

Table 6 The rigourousness of selected full economic evaluations: a summary report

\begin{tabular}{|c|c|c|c|}
\hline $\begin{array}{l}\text { Drummond et al.'s } \\
\text { check list }\end{array}$ & $\begin{array}{c}\text { COPD and } \\
\text { asthma } \\
n=20\end{array}$ & $\begin{array}{c}\text { Diabetes } \\
\text { mellitus } \\
n=15\end{array}$ & $\begin{array}{c}\text { Rheumatoid } \\
\text { arthritis } \\
n=8\end{array}$ \\
\hline No evaluation possible ${ }^{b}$ & 4 & 2 & 2 \\
\hline \multicolumn{4}{|l|}{ Number of articles with } \\
\hline Good research question & 13 & 12 & 4 \\
\hline $\begin{array}{l}\text { Description of } \\
\text { altematives }\end{array}$ & 12 & 9 & 5 \\
\hline $\begin{array}{l}\text { Evidence of } \\
\text { effectiveness }\end{array}$ & 8 & 11 & 4 \\
\hline $\begin{array}{l}\text { All costs/outcomes } \\
\text { identified }\end{array}$ & 7 & 9 & 5 \\
\hline $\begin{array}{l}\text { Costs/outcomes } \\
\text { measured well }\end{array}$ & 11 & 10 & 5 \\
\hline $\begin{array}{l}\text { Costs/outcomes valued } \\
\text { credibly }\end{array}$ & 5 & 5 & 5 \\
\hline Discounting & 2 & 6 & 1 \\
\hline Incremental analysis & 4 & 1 & 3 \\
\hline Sensituvity analysis & 2 & 5 & 2 \\
\hline Presentation complete & 11 & 9 & 4 \\
\hline $\begin{array}{l}\text { a Adjusted on the basis of Rutt } \\
\text { b Officially published as an abs }\end{array}$ & $\begin{array}{l}\text { act onty } \\
\text { act }\end{array}$ & tal. ${ }^{22}$ & \\
\hline
\end{tabular}


cular diseases, gangrene and amputation. The numerous side-effects incur heavy medical costs. Diabetic retinopathy affects approximately half of the people with diabetes, causing substantial societal costs of blindness in terms of lost production. ${ }^{28}$ Nevertheless, most studies focused on the direct costs only, with a few studies on the cost of illness aspects of DM. ${ }^{29-31}$ The health cost of diabetes is estimated to account for 4-5\% of all health care expenditures. Other social i.e. indirect costs, due to lost production and premature death, account for $40-50 \%$ of total cost of illness. ${ }^{29}$

Until now, there have been a few intervention studies focusing on the effectiveness of $\operatorname{diet}^{32}$ or medication. ${ }^{33}$ Table 7 shows that most economic appraisal has been dedicated to screening, ${ }^{34-38}$ sometimes combined with treatment, ${ }^{39-42}$ and to educational activities. ${ }^{43-45}$ The other articles cover diet, ${ }^{46}$ insulin therapy, ${ }^{47}$ and a programme with different locations of care. ${ }^{48}$

With 11 references, CEA is the most frequently performed type of study. CBA has been performed 3 times ${ }^{35,38,41}$ and CUA only once. ${ }^{46}$ Three references ${ }^{40-42}$ originated from the same research group, all using the same populationbased simulation model.

Screening and treatment of diabetic retinopathy received a good deal of attention, accounting for $60 \%$ of all references and has been proven to be cost-effective from a societal and governmental perspective. From the viewpoint of a third-party payer, however, some additional incentives might be necessary. ${ }^{46}$ Screening for the early detection of diabetic retinopathy is a very cost-effective strategy, even if only $60 \%$ of the insulin-dependent patients are being covered. Each person receiving comprehensive eye examinations and appropriate treatment at the earliest signs of disease represents a savings of nearly 10.000 US\$. $.0,41$
For cases of retinopathy detected early, laser surgery can prevent further damage to the eye, with a success rate of nearly $90 \%$. Unfortunately, it is not easy to detect diabetic retinopathy, because no noticeable loss of vision appears until the damage is well advanced.

In The Netherlands, a recent full economic evaluation of ophthalmic care, including ophthalmoscopy and photocoagulation, ${ }^{18}$ demonstrated clear net benefits of screening for IDDM patients but failed to provide sufficient (economic) arguments to justify special ophthalmic care for NIDDM patients. But these findings depend on the assumptions about the age of onset of diaberic retinopathy and the actual moment of diagnosing this event: the younger the age of onset, the more favourable the cost-effectiveness ratios. Screening for NIDDM did prove to be cost-effective, although less so than for IDDM because the threat of blindness is less severe. ${ }^{39}$ Annual eye examinations using dilation of the pupils has proven to be the most effective screening strategy, both in the $\mathrm{USA}^{39}$ and in Sweden, ${ }^{40}$ even for relatively low rates of compliance.

Health education programmes have been studied more frequently than suggested by table 6 , accounting for almost $20 \%$ of all references in the economic literature, but full economic evaluation studies have been reported only 3 times. ${ }^{43-45}$ Less popular are diet and nutrition (although good for the single cost-utility study, focusing on a diet plus exercise programme for NIDDM), ${ }^{46}$ and out-patient activities. ${ }^{47}$ Antibiotics against osteomyelitis, which is part of the natural progression of diabetes in the lower extremities, is not effective, but early amputation of the toe in combination with antibiotics has proven to be cost-effective. ${ }^{49}$

In general, many behavioural and education programmes for diabetes seem to be cost-beneficial, ${ }^{28,50}$ although there is little really strong evidence and some questions remain

Table 7 Economic appraisal of dıabetes mellıtus: main characterıstıcs of the studies, by intervention $(n=15)$

\begin{tabular}{|c|c|c|c|c|c|c|c|c|}
\hline \multirow{2}{*}{\multicolumn{3}{|c|}{ First author, year and [ref.no] }} & \multirow{3}{*}{$\frac{\text { Type of study }}{\text { CEA }}$} & \multirow{3}{*}{$\begin{array}{l}\text { Type of intervention } \\
\text { Screening }\end{array}$} & \multicolumn{4}{|c|}{ Charactersstics of patient/study population(s) } \\
\hline & & & & & \multirow{2}{*}{$\frac{\text { Diagnosis }}{\text { Retinopathy }}$} & \multirow{2}{*}{$\frac{N}{-}$} & \multirow{2}{*}{$\frac{\text { Groups }^{2}}{2}$} & \multirow{2}{*}{$\frac{\text { Random }}{\text { Yes }}$} \\
\hline Drummond & 1992 & [34] & & & & & & \\
\hline Foulds & 1983 & [35] & CBA & Screening & Retinopathy & - & 2 & No \\
\hline Lairson & 1992 & {$[36]$} & CEA & Screening & Retinopathy & 352 & 4 & No \\
\hline Sculpher & 1991 & {$[37]$} & CEA & Screening & Retinopathy & 3,318 & 3 & No \\
\hline Waugh & 1986 & [38] & CEA & Screening & Retinoparhy & - & 2 & No \\
\hline Dasbach & 1991 & [39] & $\mathrm{CEA}^{\mathrm{b}}$ & Screenung and treatment & Retinopathy & - & 3 & No \\
\hline Fendrick & 1992 & {$[40]$} & $\mathrm{CBA}^{\mathrm{b}}$ & Screening and treatment & Retinopathy & 750 & - & No \\
\hline Javitt & 1989 & {$[41]$} & $\mathrm{CEA}^{\mathrm{b}}$ & Screenıng and treatment & Retinopathy & 31,000 & - & No \\
\hline Javitt & 1991 & {$[42]$} & $\mathrm{CEA}^{\mathrm{b}}$ & Screening and treatment & Retınopathy & 17,245 & - & No \\
\hline Kacerovsky-Btelesz & 1984 & {$[43]^{\mathrm{c}}$} & $\mathrm{CBA}$ & Education & IDDM/NIDDM & 300 & 2 & $?$ \\
\hline Weerdt & 1991 & [44] & CEA & Education & IDDM & 558 & 2 & Yes \\
\hline Chen & 1991 & {$[45]^{c}$} & CEA & Education and monitoring & NIDDM & 89 & 2 & Yes \\
\hline Kaplan & 1988 & [46] & CUA & Diet, exercise & NIDDM & 76 & 2 & Yes \\
\hline Mengistu & 1991 & [47] & CEA & Insulin therapy & IDDM/NIDDM & 104 & 2 & Yes \\
\hline Schefflet & 1992 & {$[48]$} & CEA & Total programme & Pregnancy DM & 189 & 2 & Yes \\
\hline
\end{tabular}

a Number of groups

b Computer simulation based on secondary data analyses

c Officially published as an abstract only 
to be solved, such as the long-term effects and the effectiveness of application in a more representative patient population instead of self-selected patients. Education programmes tend to focus on nutrition and exercise, because in Western societies 60-90\% of NIDDM patients are obese. ${ }^{51}$ In fact, NIDDM is rarely observed in countries where food supplies are limited. ${ }^{52}$ The American Diabetes Association therefore suggested that pharmacological management of NIDDM should not begin until a serious programme of diet and exercise has failed to produce improved glucose tolerance. ${ }^{53}$ New advances in treatment, such as new insulins, new monitoring methods at home and pumps to replace syringes may improve patients' quality of life and reduce costs, but have yet to be evaluated. 28

\section{Rheumatoid arthritis}

Rheumatoid arthritis affects the quality of life of patients over a very long period of progressing disease with periodic flare-ups and remissions. In The Netherlands, nearly $8 \%$ of all elderly above 65 years suffer from arthritis, either in the feet and hands or of other kinds; more strictly, 2-3\% suffer RA (table 1). Using MEDLINE we found almost 28,000 references to RA during the period 1984-1993 of which $6.7 \%$ had been dedicated to evaluation. However, we found only 8 full economic studies (5 CEA's, 1 CBA and 2 CUA; table 8). From a societal perspective, this lack of research is not very justifiable, because of the fact that the burden of RA to parients and society is quite large. All musculoskeletal diseases together account for 5-9\% of all direct medical expenses. ${ }^{54}$ This is probably an underestimation, because direct and out-of-pocket expenses for medication are not registered properly by disease category and yet are very important for RA. Additionally, the indirect costs account for 50 to even $85 \%$ of all costs, ${ }^{54}$ so patients with RA are incurring substantial indirect monetary costs, especially earnings losses, ${ }^{55,56}$ and intangible costs of pain, disability and consequent depression in addition to significant direct costs. ${ }^{54,57}$

Three studies focused on medication, 2 for patients with rheumatoid arthritis 58,59 and 1 for patients with osteoarthritis. ${ }^{60}$ Thompson et al. ${ }^{58}$ evaluated the cost-effectiveness of auranofin (an oral gold preparation) in a randomized trial of RA patients with a placebo control group and found significant, albeit slight, improvements in 4 out of 6 clinical outcome parameters and 1 negative side-effect (diarrhoea). However, medical costs (including paid help) and indirect costs (travelling time of patients and work disability) were higher for the experimental group. Kvien et al. ${ }^{60}$ concluded that a variable dosing regimen of naproxen for patients with knee and hip arthritis is superior to a fixed regimen, resulting in a lower drug consumption (by 20-30\%), similar levels of efficacy and possibly better tolerance.

Two other studies focused on different surgical strategies for total joint arthroplasty ${ }^{61}$ and advanced degenerative knee arthritis. ${ }^{62}$ In the larter study, which used a model simulating 25 years of experience from primary surgery at age 40 years and included a sensitivity analysis, total knee arthroplasty dominated 3 other surgical strategies, such as unicompartmental resurfing and tibial osteotomy. Although total joint arthroplasty in itself is rather expensive, other direct costs of medical and long-term care are much lower. ${ }^{61-64}$ However, further evidence based on randomized trials with different strategies is necessary.

The sixth study is a very early full economic evaluation (1969), addressing a wide range of RA treatments at a rheumatic centre (a 48 bed hospital) in Glasgow. ${ }^{65}$ The present value of benefits exceeded total costs under all assumptions explored in the sensitivity analysis, but the treatment at the centre was not compared to any other alternative (implicitly 'doing nothing').

The last 2 studies compared 2 different locations of care for patients with theumatoid arthritis, i.e. in-patient care with intensive out-patient therapy. ${ }^{66,67}$ In the latter study, hospitalization improved by a factor of 3 but costs were a factor of 2.5 higher. Thus, although this study found slightly better outcomes at substantially higher costs, society might be reluctant to invest in the new alternative, because of concern for the national health care budget, although such a strategy would clearly improve the quality of life of patients. ${ }^{54,58,61}$ Other researchers, although not undertaking a full economic evaluation, did not find any possibilities of achieving significant reductions of hospitalization rates for RA patients. ${ }^{68,69}$

Table 8 Economic appraisal of theumatoid arthritis: main characteristics of the studies, by intervention $(n=8)$

\begin{tabular}{|c|c|c|c|c|c|c|c|c|}
\hline \multirow{2}{*}{\multicolumn{3}{|c|}{ Fust author, year and [ref.no] }} & \multirow{3}{*}{$\frac{\text { Type of study }}{\text { CEA }}$} & \multirow{3}{*}{$\frac{\text { Type of intervention }}{\text { Medication }}$} & \multicolumn{4}{|c|}{ Characteristics of patient/study population(s) } \\
\hline & & & & & \multirow{2}{*}{$\begin{array}{l}\text { Diagnosis } \\
\text { Rheumatoid arthritis }\end{array}$} & \multirow{2}{*}{$\frac{N}{293}$} & \multirow{2}{*}{$\frac{\text { Groups : }}{2}$} & \multirow{2}{*}{$\frac{\text { Random }}{\text { Yes }}$} \\
\hline Thompson & 1988 & {$[58]$} & & & & & & \\
\hline Edelson & 1990 & [59] & CEA & Medication & Rheumatoid arthritis & - & 2 & Yes \\
\hline Kvien & 1991 & {$[60]$} & CEA & Medication & Osteoarthritis & 356 & 2 & Yes \\
\hline Liang & 1986 & [61] & CUA & Total joint arthroplasty & Osteoarthritis & - & 4 & No \\
\hline Macintyre & 1991 & {$[62]^{c}$} & $\mathrm{CUA}^{\mathrm{b}}$ & Surgical strategies & Knee arthritis & 45 & 2 & No \\
\hline Brooks & 1969 & {$[65]$} & $\mathrm{CBA}$ & Rheumatic centre & Rheumatoid diseases & 115 & 3 & No \\
\hline Pettingill & 1980 & {$[66]^{c}$} & CEA & Location of care & Rheumatoid arthritis & 119 & 2 & No \\
\hline Helewa & 1989 & {$[67]$} & CEA & Location of care & Rheumatoid arthritis & 71 (women) & 2) 2 & Yes \\
\hline
\end{tabular}


The results from this part of the review are not promising, but are slightly misleading as long as they do not take into account the non-economic aspects of chronic diseases, such as the quality of life of RA patients, who are willing to pay quite a large part of their income for treatment of their disease. ${ }^{70}$

Chromic obstructive pulmonary diseases and asthma COPD is generally used as a broad term for chronic bronchitis, emphysema, and chronic air-flow limitation. In English language literature, asthma is distinguished from COPD, following international consensus. In The Netherlands, the combined prevalence rates of the 2 conditions (encompassed in the acronym Cara) vary from 10-20\% for men (especially elderly men suffer from COPD) and 5-10\% for women or children who especially suffer from asthma (table 1). Approximately $4 \%$ of all health care costs are caused by COPD and asthma. The associated burden of illness is considerable and will increase further because of ageing. ${ }^{71}$ Continuous search during recent years resulted in 20 full economic studies published over the years 1980-1991. Earlier, Rutten-Van Molken et al. reported on this subject. ${ }^{22} \mathrm{~W}$ ith some additional references, table 9 has been adapted from that source.

Most of these studies related to asthma are concerned with health educational programmes, either for children, ${ }^{72-74}$ adults ${ }^{75-77}$ or borh. ${ }^{78}$ These types of interventions are relatively inexpensive and in children even seem to result in actual savings. Compliance has often been proven to increase. ${ }^{77}$ Conclusions about home care as a substitute for institutional care for COPD are not decisive: some indicate no cost reductions, ${ }^{79,80}$ while others conclude in favour of home care. ${ }^{81,82}$ In highly selected patient populations, home care seems to be cost-effective, especially if the communication and coordination between community care and the treating physician is well organized. ${ }^{22}$ Other popular themes in the literature are oxygen therapy 83,84 and breathing support aids. ${ }^{85,86}$ Chronic obstructive airways disease is the only COPD disorder studied in detail, with favourable results for oxygen therapy. ${ }^{87}$ The simple metred dose inhaler is a more effective aerosol drug delivery method than the updraft nebulizer, ${ }^{88}$ for both exacerbated obstructive lung disease, ${ }^{86}$ and intubated mechanically ventilated patients. ${ }^{87}$ Portable oxygen cylinders for patients during exercise have not been proven cost-effective; the major result is improvement of quality of life. ${ }^{89}$

Pharmacotherapy, although currently the most important therapeutic intervention for asthma and COPD (with more than 25 different drugs in different delivery forms in The Netherlands alone), ${ }^{90}$ has been evaluated by economists only 3 times, twice for COPD 91,92 and once for asthma, with favourable results for cromolyn sodium. ${ }^{93} \mathrm{~A}$

Table 9 Economic appraisal of COPD and asthma: main characterıstics of the studies, by intervention $(n=20)^{2}$

\begin{tabular}{|c|c|c|c|c|c|c|c|c|}
\hline \multirow{2}{*}{\multicolumn{3}{|c|}{ First author, year and [ref.no] }} & \multirow{3}{*}{$\frac{\text { Type of study }}{\text { CEA }}$} & \multirow{3}{*}{$\frac{\text { Type of intervention }}{\text { Education (children) }}$} & \multicolumn{4}{|c|}{ Characteristics of patient/stucty population(s) } \\
\hline & & & & & \multirow{2}{*}{$\begin{array}{l}\text { Diagnosis } \\
\text { Asthma }\end{array}$} & \multirow{2}{*}{$\frac{N}{310}$} & \multirow{2}{*}{$\frac{\text { Groups }^{b}}{2}$} & \multirow{2}{*}{$\frac{\text { Random }}{\text { Yes }}$} \\
\hline Clark & 1986 & [72] & & & & & & \\
\hline Fireman & 1981 & {$[73]$} & CEA & Education (children) & Asthma & 26 & 2 & No \\
\hline Lewis & 1984 & {$[74]$} & CEA & Education (children) & Asthma & 76 & 2 & Yes \\
\hline Deter & 1986 & [75] & $\mathrm{CBA}$ & Education (adults) & Asthma & 22 & 2 & No \\
\hline Wilson & 1987 & {$[76]$} & CEA & Education (adults) & Asthma & 300 & 4 & Yes \\
\hline$W_{1 n d s o r}$ & 1990 & [77] & CEA & Education (adults) & Asthma & 267 & 2 & Yes \\
\hline Shields & 1985 & {$[78]^{d}$} & CEA & Education (all) & Asthma & 387 & 2 & Yes \\
\hline Bergner & 1988 & [79] & CEA & Home care & COPD & 301 & 3 & Yes \\
\hline Campbell-Haggerty & 1991 & {$[81]$} & CEA & Home care & COPD, asthma & 17 & 1 & - \\
\hline Dranove & 1985 & {$[80]$} & CEA & Home care & COPD & 436 & 2 & No \\
\hline Ström & 1990 & {$[83]$} & CEA & Oxygen delivery & COPD & 41 & 2 & No \\
\hline Tiep & 1987 & {$[84]$} & CEA & Oxygen delivery & COPD & 9 & - & - \\
\hline Schmidt & 1983 & {$[85]$} & CEA & Mechanical ventilation & COPD, others & 137 & 1 & - \\
\hline Jasper & 1987 & {$[86]$} & $\mathrm{CBA}$ & Aer. bronch. delivery ${ }^{e}$ & COPD, asthma & 36 & 2 & Yes \\
\hline Gay & 1991 & {$[87]$} & CEA & Aer. bronch. delivery ${ }^{e}$ & Aurways obstruction & 18 & 2 & Yes \\
\hline Hay & 1991 & {$[91]$} & $C E A^{c}$ & $\begin{array}{l}\text { Medication } \\
\text { (alpha-1 antitrypsin) }\end{array}$ & COPD & - & - & - \\
\hline Jubran & 1991 & {$[92]^{d}$} & CEA & $\begin{array}{l}\text { Medication } \\
\text { (bronchodilators) }\end{array}$ & COPD & 133 & 2 & Yes \\
\hline Ross & 1988 & [93] & $\mathrm{CBA}$ & $\begin{array}{l}\text { Medication } \\
\text { (chromolyn sodium) }\end{array}$ & Asthma & 53 & 2 & No \\
\hline Johnson & 1983 & {$[97]^{\mathrm{d}}$} & $\mathrm{CBA}$ & Rehabilitation & COPD & 194 & 2 & No \\
\hline Toevs & 1984 & {$[98]$} & CUA & Rehabilitation & COPD, asthma & 76 & 2 & Yes \\
\hline
\end{tabular}

a Adapted (with some additional references) from Rutten-Van Molken et al. ${ }^{22}$

b Number of groups

c Simulation model based on secondary data analyse

$\mathrm{d}$ Officially published as an abstract only

e Aerosol bronchodilator delivery 
Dutch multicentre randomized intervention trial in asthma and COPD has proven that long-term therapeutic intervention directed at reducing bronchoconstriction and airways hyper-responsiveness, adding corticosteroids to a regimen of beta-2-agonists, is more cost-effective than treatment with a beta-2-agonist plus an anticholinergic drug; the latter in turn is superior to therapy with a single bronchodilating agent. ${ }^{90,94,95}$ The same favourable results hold for children. ${ }^{96}$

Rehabilitation programmes have been subject to $\mathrm{CBA}^{97}$ and CUA. ${ }^{98}$ The latter is the only CUA we found in the economic literature on COPD and asthma. This is remarkable, because the quality of life as an outcome measure of interventions is equally or even more important than quantity of life or other outcome measures. 99,100 Behavioural programmes to improve compliance to exercise and rehabilitation have proven to be effective. ${ }^{97,98}$ However, the samples used in these studies (table 9) are too small for firm conclusions. Most studies indicate that the selection of patients is still difficult, but very important in determining the cost-effectiveness profile.

\section{DISCUSSION}

Discussions on the limits to health care growth, in relation to the financial problems of governments and partially triggered by demographic, epidemiological and technological trends, have raised the question of effectiveness and efficiency of health care programmes. Although the importance of efficient allocation of resources is growing, application of full economic evaluation in health policy decision making is rare. ${ }^{101}$ Until now, there is little reliable evidence in the fields of care for the chronically ill and elderly on which policy choices can be based. It is unclear how the complex demands of these patient groups can be influenced, what the most cost-effective ways are to accommodate this demand and which mechanisms are most instrumental in achieving efficient resource allocation. 102

Our review shows that in chronic diseases full economic evaluation, which we used here in the strict definition, i.e. excluding cost (-minimization) analysis, is scarce. We were able to locate 20 publications on COPD/asthma, 15 on diabetes mellitus and 8 on rheumatoid arthritis. These studies account for $0.2 \%$ of all publications concerning these diseases during the period 1984-1993.

In chronic diseases, economists generally used CEA (in more than $70 \%$ of the studies), followed by CBA (20\%) and CUA (9\%). In rheumatoid arthritis CUA has been done slightly more often (25\%). These conclusions confirm the findings in the economic bibliography. ${ }^{21}$

Our review has revealed some caveats in the methodology of full economic studies of programmes targeted at COPD/asthma, RA and DM. These results are consistent with the findings of Drummond et al. ${ }^{15}$ and Maynard ${ }^{9}$ that the methods of full economic evaluation (especially CUA) are still in the phase of development, ${ }^{101}$ so that economic studies have seldom satisfied a critical review. Although most studies (in this review approximately $85 \%$ ) do state a clear research question and give substan- tiated evidence of the effectiveness of a particular intervention (66\%), based on a detailed description of alternatives (75\%), only one-fifth of all studies include discounting of different time profiles of costs and outcomes or an incremental analysis or a sensitivity analysis. Approximately one-third of all studies reviewed in this article could be improved by including a comprehensive description of all relevant alternatives and all relevant costs and consequences of each alternative, measured and valued properly (table 6). Care needs to be taken that marginal costs and benefits are measured relative to their highestvalued alternative use. An appropriate comparator can or cannot be 'current practice' or 'doing nothing', but this decision will produce a particular configuration of marginal costs and benefits. ${ }^{103}$

Full economic evaluation in COPD/asthma, RA and DM has revealed many effective interventions in chronic diseases. Some programmes for early discharge from hospitals are cost-effective for certain groups of RA patients, although the results in different locations of care are not decisive and less favourable when the total costs of home care and informal care are fully included. The same holds for home care (as an alternative to institutional care) for DM and COPD/asthma. In highly selected patient populations, home care seems to be cost-effective but effect measures are frequently hampered by small samples and intervening factors. Pharmacotherapy did not get much attention, although it is often an important therapeutic intervention, especially in COPD/asthma. All the studies we found came up with favourable results. The small number of studies is probably due to the fact that it is unethical to withhold effective medication from control groups; 'doing nothing' is not a realistic alternative.

Screening and treatment of diabetic retinopathy received a good deal of attention, accounting for $60 \%$ of all DM references and has been proven to be very cost-effective, especially for IDDM and even for less favourable coverage and compliance rates. Behavioural and education programmes, which are of special interest to patients with asthma or DM, seem to be cost-beneficial, although the long-term effects and the possibilities of generalizing results to the population remain questionable. This review makes it clear that the selection of patients is very important for the cost-effectiveness profile, but still remains difficult.

There are many problems and challenges to applying economic appraisal to chronic diseases. It is difficult to acquire precise cost data in relation to individuals consuming medical and social services, in and outside institutions, comparing the real costs of alternatives for specific groups of individuals. Secondly, one has to make arbitrary decisions to split so-called joint costs when comparing different service patterns for a group of individuals. Other problems are related to co-morbidity, heterogenity in need and demand for care, effects of supply-induced demand by offering new forms of care, the problem of preference drift (as shown here for COPD) and consequent conceptual problems with the meaning and measurement of quality of life. Costs and financing should be 
clearly distinguished; governmental agencies tend to focus on the latter, thus limiting the perspective of the study and 'forgetting' that the financial burden of long-term home care programmes shifts from public to private funding with consequent cumulative effects for chronic and elderly patients, who are already in the lower social classes. The problem of measurement and valuation of informal care has rarely been tackled effectively until now, but is very important in chronic and long-term care. 7,30

In the care sector, objective measurement of outcome is much more difficult than in the cure sector and sometimes even impossible. Problematic to the economic evaluation of alternative location of care strategies is that home care is a basket of very different activities of different professionals, resulting in many identification problems (which intervention causes which effect?). Services in the chronic care sector are meant to serve many objectives, which go beyond the single dimension of health status. These objectives have to be made explicit in order to develop indicators to fully assess the outputs of an intervention. Standardized generic quality of life instruments are needed to allow comparisons between various interventions, ${ }^{104}$ but additional disease-specific measures and questionnaires are necessary ${ }^{105}$ and will also increase the sensitivity to change. ${ }^{100,106}$

Intermediary outcome measures, like, for instance, referral patterns or length of stay, may say something about the process of care, but often do not provide sufficient information for an economic appraisal. Most relevant is probably the subjective measurement of outcome, asking chronic patients to assess the outcomes of services. More fundamentally, there is a need to use an integrated utility concept. Health status, pain, comfort, safety and independence are relevant dimensions of a broad concept of well-being in the chronically ill, as has been illustrated for rheumatoid arthritis. ${ }^{58,61,107}$ The concepts underlying the chronic care go far beyond the statement of Gerard and Mooney that "only health gain is being sought from health care resources". ${ }^{103}$ The challenge remains to operationalize these concepts and make them applicable to economic evaluation of health care programmes for the chronically ill.

This article was presented as a keynote lecture at the conference 'Chronic diseases and changing care patterns in an ageing society', Arnsterdam. The Netherlands, 9-11 June 1993.

Without claiming any responsibility for the contents of this article, the author is indebted to the research assistance of J. van Rijn and C.A.M. Bossink and to the comments on earlier drafts by M.M.Y. de Klerk and Professor F.F.H. Rutten.

\section{REFERENCES}

1 Tugwell P, Bennett KJ, Sackett DL, Haynes RB. The measurement iterative loop: a framework for the critical appraisal of need, benefits and costs of health interventions. J Chronic Dis 1985:38;339-51.

2 Ruwaard D, Kramers P-GN, Berg Jeths A van den, Achterberg PW. Public health status and forecasts; the health status of the Dutch population over the period 1950-2010. Den
Haag: National Institute of Public Health and Environmental Protection/SDU, 1994.

3 Walker A, Alber J, Guillemard A. Older people in Europe: social and economic policies; the 1993 report of the European Observatory. Brussels: Commission of the European Communities, 1993.

4 Central Bureau of Statistics. Bevolkingsprognose 1989-2035. Voorburg: CBS, 1989.

5 Huijsman R. Care provisions for the elderly: a review. In: Coolen JAI, ed. Changing care for the elderly in the Netherlands. Assen/Maastricht: Van Gorcum Publishers, 1993:23-45.

6 Huijsman R, Woltson DJ. Demand and supply, Siamese twins in the care for the elderly? Public Financerfinances Publiques 1993:48(Suppl.):322-42.

7 Koopmanschap MA, Roijen L van, Bonneux L, Bonsel GJ, Rutten FFH, Maas $P J$ van der. Cost of diseases in international perspective. Eur J Public Hlth 1994;4:258-64. (Also in: Koopmanschap MA. Complementary anahyses in economic evaluation of health care [dissertation]. Rotterdam: Erasmus Universiteit, 1994.)

8 Klerk MMY, Huijsman R. Actual and potential use of home care technology by the elderly. In: Wild C, Kirschner A, eds. Safety-alarms systems, technical aids and smart homes. Knegsel, The Netherlands: The Akon Series, 1994;8:117-34.

9 Maynard A. Which medical therapies are proven? (editorial). Hith Econ 1992; 9 (Suppl.):1-2.

10 Drummond MF, Stoddart GL, Torrance GW. Methods for the economic evaluation of health care programmes. Oxford: Oxford Medical Publications, 1987.

11 Martens LL. The cost-effectiveness of cholesterol-lowering therapy with simvastin in the primary prevention of coronary heart disease in the Netherlands [thesis]. Rotterdam: Erasmus University, 1992.

12 Broome J. Qalys. J Public Econ 1993;50:149-67.

13 Mehrez A. Gafni A. Quality-adjusted-life-years, utility theory and healthy-years-equivalents. Med Decision Making 1989;9:142-9.

14 Bleichrodt H, Gafni A. HYYs: the second generation of outcome measures in health. Rotterdam: Erasmus University, Institute for Medical Technology Assessment, 1993.

15 Drummond M, Brandt A, Luce B, Rovira J. Standardizing methodologies for economic evaluation in health care; practice problems and potential. Int J Technol Assess 1993;9:26-36.

16 Rutten FFH, Hout BA van, Ommen $R$ van, Ineveld BM van, Hujjsman R. Kostenberekening bij gezondheidszorgonderzoek: richtlijnen voor de praktijk. Utrecht: Van Arkel, 1993.

17 Avorn J. Benefit and cost analysis in geriatric care. New Engl J Med 1984;310:1294-301.

18 Crijns HHM. Diabetic retinopathy; a cost effectiveness analysis of ophthalmoscopy and photocoagulation [dissertation]. Rotterdam: Erasmus University, 1993.

19 Martens LLM, Doorslaer EKA van. Dealing with discounting. Int J Technol Assess 1990;6:139.

20 Parsonage $M$, Neuburger $H$. Discounting and health effects. H/th Econ 1991:1;71-6.

21 Backhouse ME, Backhouse R, Edey SA. Economic evaluation bibliography. HIth Econ 1992;1:1-236.

22 Rutten-van Molken MPMH, Doorslaer EKA van, Rutten FFH. Economic appraisal of asthma and COPD care: a literature review 1980-1991. Soc Sci Med 1992;35:161-75.

23 Drummond MF, Torrance GW, Mason J.

Cost-effectiveness league tables: more harm than good? Soc So Med 1993;37:33-40.

24 Navarro JDN. Diabetes in the United Kingdom: some facts and figures. Diabetic Med 1988;5:816-22.

25 Steering Committee on Future Health Scenarios. Chronic diseases in the year 2005. Part 1: Scenarios on diabetes mellitus. Utrecht: Bohn, Scheltema \& Holkema, 1990.

26 Harris MI, Hadden WC, Knowter WC, Bennett PH. Prevalence of diabetes mellitus and impaired glucose tolerance and plasma glucose levels in US population aged $20-74$ years. Diabetes 1987;36:523-34.

27 Mooy JM, Grootenhuis PA, Vries H de, Heine RJ, Bouter LM. De Hoorn study. disorders of glucose tolerance in a general caucasian population. The Netherlands Journal of Medicine 1992;41:A29-30.

28 Ackerman SJ. Benefits of preventive programs in eye care are visible on the bottom line. Diabetes Care 1992;15:580-1. 
29 Leese $B$. The costs of diabetes and its complications.

Soc Sci Med 1992;35:1303-10.

30 Gerard K, Donaldson C, Maynard AK. The cost of diabetes.

Diabetic Med 1989;6:164-70.

31 Jonsson B. Diabetes; the cost of illness and the cost of control. Acta Med Scand 1983;671(Suppl.):19-27.

32 Geppert J, Splett PL. Summary document of nutrition intervention in diabetes. J Am Diet Assoc 1991;91(Suppl.):S27-35.

33 Feskens EJM. Epidemiological studies on glucose tolerance in relation to dietary determinants and cardiovascular risks [thesis]. Leiden: University of Leiden, 1991.

34 Drummond MF, Davies LM, Ferris, FL. Assessing the costs and benefits of medical research: the diabetic retinopathy study. Soc Sci Med 1992;34:973-81.

35 Foulds WS, MacCuish A, Barrie T, et al. Diabetic retinopathy in the west of Scotland: its detection and prevalence, and the cost-effectiveness of a proposed screening programme. HIth Bull 1983:41:318-26.

36 Lairson DR, Pugh JA. Cost-effectiveness of alternative methods for diabetic retinopathy screening. Diabetes Care 1992;15:1369-77.

37 Sculpher MJ, Buxton MJ, Ferguson BA, et al. A relative cost-effectiveness analysis of different methods of screening for diabetic retinopathy. Diabetic Med 1991;8:644-50.

38 Waugh NR, Ellingford A, Scott SD. Screening for diabetic retinopathy: options and cost effectiveness. Pract Diabetes 1986;3:30-1.

39 Dasbach EJ, Fryback DG, Newcomb PA, Klein R, Klein BEK Cost-effectiveness of strategies for detecting diabetic retinopathy. Med Care 1991;29:20-39.

40 Fendrick AM, Javitt JC. Chiang YP. Costeffectiveness of the screening and treatment of diabetic retinopathy. Int J Technol Assess 1992;8:694-707.

41 Javitt JC Canner JK, Sommer A. Cost effectiveness of current approaches to the control of retinopathy in type I diabetics. Ophthalmology 1989;96:255-64.

42 Javitt JC, Aiello LP, Bassi U, Chiang YP, Canner JK. Detecting and treating retinopathy in patients with type diabetes mellitus. Ophthalmology 1991;98:1565-73.

43 Kacerowsky-Bielesz G, Hohonecker J, Schindler H, Willms B Teaching of diabetic patients as an important part of the treatment of diabetes mellitus; a cost benefit analysis (abstract) Diabetologica 1984;27:A293-4.

44 Weerdt I de, Visser AP, Kok GJ, Weerdt $O$ de, Veen EA van der. Randomised controlled multicentre evaluation of an education programme for insulin treated patients with diabetes: effects on metabolic control, quality of life and costs of therapy. Diabetic Med 1991;8:338-45.

45 Chen X, Yao Q, Eisenberg JM, Glick H, Norma, SA Cost-effectiveness of education and home glucose monitoring in uncontrolled non-insulin-dependent-diabetics in Shanghai (abstract). Med Decision Making 1991;11:326.

46 Kaplan RM, Atkins CJ, Wilson DK. The cost-utility of diet and exercise interventions in non-insulin-dependent diabetes mellitus. Hith Promot 1988;2:331-40.

47 Mengistu $M$, Lungi $Y$, Mamo F. Inpatient or outpatient initiation of insulin therapy: experiences and cost-effectiveness analysis in a suboptimal dinical setting. Trop Geograph Med 1991;43:180-3.

48 Scheffler RM, Feuchtbaum LB, Phibbs CS. Prevention: the cost-effectiveness of the California diabetes and pregnancy program. Am J Public HIth 1992;82:168-75.

49 Benton GS, Kernstein MD. Cost effectiveness of early digit amputation in the patient with diabetes. Surgery, Gynaecol Obstet 1985;161:523-4.

50 Connor $\mathrm{H}$. Diabetic management and education: costs and benefits. In: Balesi AK, Hide DW, Giles G, eds. Diabetes Education. New York: Wiley \& Sons, 1984.

51 Davidson MB. Diabetes mellitus diagnosis and treatment. New York: John Wiley \& Sons, 1981.

52 West KM. Epidemiology of diabetes and its vascular lesions. New York: Elsevier, 1978.

53 American Diabetes Association. The physicians guide to type II diabetes (NIDDM). New York: American Diabetes Association, 1984.

54 Yelin E. Health care research and technology. Curr Opin Rheumatol 1990;2:327-35. outcomes in meumatoid arthritis and osteoarthritis. Arthritis Rheumat 1984;27:522-9.

56 Kramer JS, Yelın EH, Epstein WV. Social and economic impacts of four muscoloskeletal diseases. Arthritis Rheumat 1983;26:901-7.

57 Pincus T, Mitchell JM, Burkhauser RV. Substantial work disability and earnings losses in individuals less than age 65 with osteoarthritis: comparisons with rheumatoid arthritis. J Clin Epidemiol 1989:42:449-57.

58 Thompson MS, Read UL Hutchings HC, Paterson M, Harris ED. The cost effectiveness of aurofin: results of a randomized clinical trial. J Rheumatol 1988;15:35-42. 59 Edelson JT, Tosteson ANA, Sax P. Cost-effectiveness of misoprostol for prophylaxis against nonsteroidal anti-inflammatory drug-induced gastrointestinal tract bleeding. J Am Assoc 1990;264:41-7.

60 Kvien TK, Brors O, Staff PH, Rognstad S, Norby J. Improved cost-effectiveness ratio with a patient self-adjusted Naproxen dosing regimen in osteoarthritis treatment. Scand J Rheumatol 1991;20:280-7.

61 Liang MH, Cullen KE, Larson MG, et al. Cost-effectiveness of total joint arthroplasty in osteoarthritis. Arthritis Rheumat 1986-29:937-43.

62 Macintyre JD, Scheck AC, Minas T, Weinstein MC Costeffectiveness analysis of surgical strategies for knee arthritis in middle-aged adults (abstract). Med Decision Making 1991;11:332.

63 Keet JGM. Kosten-batenanalyse van de totale heupprothese (Cost-benefit analysis of total hip arthroplasty). Tijdschr Geneesk 1987;131:1965-9. (In Dutch)

64 Jonsson B, Larsson SE. Functional improvement and costs of hip and knee arthroplasty in destructive theumatoid arthritis. Scand I Rheumatol 1991;20:351-7.

65 Brooks RG. Cost-benefit analysis of patients treated at a rheumatism centre. Ann Rheumat Dis 1969;28:655-61.

66 Pettingill BF. Cost-effectiveness analysis of the treatment of rheumatoid arthritis feasibility study (abstract). Clin Res 1980;28:A149.

67 Helewa A, Bombaridier C, Goldsmith $\mathrm{CH}$, Mencions B Smythe HA. Costeffectiveness of inpatient and intensive outpatient treatment of rheumatoid arthritis: a randomized clinical trial. Arthritis Rheumat 1989;32:1505-14.

68 Anderson R, Needleman R, Gatter R, Andrews R, Scarola J. Patient outcome following inpatient versus outpatient treatment of rheumatoid arthritis. J Rheumatol 1988;15:556-60.

69 Cosgrove J, Nicholas J, Barmak J, et al. Team treatment does a specialized unit improve team performance? Am J Phys Med Rehab 1988:67:253-60.

70 Thompson MS, Read JL, Liang M. Feasibility of willingness-to-pay measurement in chronic arthritis. Med Decision Making 1984;4:195-215.

71 Rutten-Van Molken MPMH, Doorslaer EKA van, Rutten FFH. Cara in cijfers: verslag van een pilot studie (Chronic non-specific lung disease: report of a pilot study). Maastricht/Rotterdam: Institute for Medical Technology Assessment, 1989. (In Dutch)

72 Clark NM, Feldman CH, Evans D, Levison MJ, Wasilewski Y, Mellins RB. The impact of health education on frequency and cost of health care use by low income children with asthma. J Allergy Clin Immunol 1986:78:108-15.

73 Fireman P, Friday GA, Gira C, Vierthaler WA, Michaels L. Teaching self-management skills to asthmatic children and their parents in an ambulatory care setting. Pediatrics 1981;68:341-8.

74 Lewis CE, Rachelefsky G, Lewis MA, Sota A de la, Kaplan M. A randomized trial of A.C.T. (asthma care training) for kids. Pediatrics 1984;74:478-86.

75 Deter HC. Cost-benefit analysis of psychosomatic therapy in asthma. J Psychosomat Res 1986;30:173-82.

76 Wilson-Pessano SR, Scamagas P, Arsham GM, et al. An evaluation of approaches to asthma self-management education for adults: the AIR/Kaiser-Permanente study. Hith Educ $Q$ 1987;14:333.

77 Windsor RA, Bailey WC, Richards JM, Manzella B, Soong S, Brooks $M$. Evaluation of the efficacy and cost effectiveness of health education methods to increase medication adherence among adults with asthma. Am I Public Hith 1990;80:1519-21. 78 Shields MC, Reinhard JD, Szidon JP. White PB. Costeffectiveness of a mastery learning program for asthmatics (abstract). Clin Res 1985;33:A732. 
79 Bergner $M$, Hudson LD, Conrad DA, et al. The cost and efficacy of home care for patients with chronic lung disease. Med Care 1988;26:566-79.

80 Dranove D. An empirical study of a hospital-based home care program. Inquiry 1985;22:59-66.

81 Campbell-Haggerty M, Stockdale-Woolley R, Nair S. Respi-car: an innovative home care program for the patient with chronic obstructive pulmonary disease. Chest 1991;100:607-12.

82 Motwani KJ, Herring GM. Home care for ventilatory dependent persons: a cost-effective humane public policy. Hlth Soc Work 1988; 13:20.

83 Stróm K, Boe J, Herala M, Boman G, Gustavii A. Assessment of two oxygen treatment alternatives in the home. Int $J$ Technol Assess Hith Care 1990;6:489-97.

84 Tiep BL, Carter R, Nicotra B, Berry J, Phillips RE, Otsap B. Demand oxygen delivery during exercise. Chest 1987;91:15-20. 85 Schmidt CD, Elliott CG, Carmelli D, et al. Prolonged mechanical ventilation for respiratory failure: a cost-benefit analysis. Crit Care Med 1983;11:407-11.

86 Jasper AC, Mohsenifar Z, Kahan S, Goldberg HS Koerner SK. Cost-benefit comparison of aerosol bronchodilator delivery methods in hospitalized patients. Chest 1987;91:614-8.

87 Gay PC, Patel HG, Nelson SB, Gilles B, Hubmayr RD. Metered dose inhalers for bronchodilator delivery in intubated mechanically ventilated patients. Chest 1991;99:66-71.

88 Scheffler RM, Delany $M$. The implications of cost-effectiveness analysis in medical technologies. Washington: Office of Technology Assessment, 1981.

89 Howard P. Cost effectiveness of oxygen therapy. Eur Respirat J 1989;2(Suppl.):637-95.

90 Rutten-Van Molken MPMH. Costs and effects of pharmacotherapy in asthma and COPD [thesis]. Maastricht: Limburg University, 1994.

91 Hay W. Robin ED. Costeffectiveness of alpha-1 antitrypsin replacement therapy in treatment of congenital chronic obstructive pulmonary disease. Am J Public HIth 1991;81:427-33. 92 Jubran A. Cost-effectiveness analysis of bronchodilators (abstract). Chest 1991, 100:555.

93 Ross RN, Morris M, Sakowitz SR, Berman BA. Cost-effectiveness of including chromolyn sodium in the treatment program for asthma: a retrospective, record-based study. Clin Therapeut 1988; 10:188-203.

94 Rutten-Van Molken MPMH, Doorslaer EKA van Jansen MCC, Kerstjens HAM, Rutten FFH. Cost-effectiveness of inhaled corticosteroids and bronchodilators in asthma and COPD. Am J Respirat Crit Care Med 1995;151 (In press).
95 Rutten-Van Molken MPMH, Doorslaer EKA van, Vliet RCIA van. Statistical analysis of cost outcomes in a randomized controlled dinical trial. Hith Econ 1994;3:333-45

96 Rutten-Van Molken MPMH, Doorslaer EKA van, Jansen MCC, Essen-Zandvliet EE van, Rutten FFH. Cost-effectiveness of inhaled corticosteroid plus bronchodilator therapy versus bronchodilator monotherapy in children with asthma. PharmacoEcon 1993:4:257-70.

97 Johnson NR, Deflorio GP, Einstein M. Cost-benefit outcomes of pulmonary rehabilitation in severe chronic obstructive pulmonary disease (abstract). Am Rev Respirat Dis 1983;127:111.

98 Toevs CD, Kaplan RM, Atkins CJ. The costs and effects of behavioral programs in chronic obstructive pulmonary disease. Med Care 1984;22:1088-100.

99 Williams SJ. Chronic respiratory illness and disability: a critical review of the psychosocial literature. Soc Sci Med 1989;28:791-803.

100 Schayck CP van, Rutten-Van Molken MPMH, Doorslaer EKA van, Weel $C$ van. Two-year bronchodilator treatment in patients with mild airflow obstruction: contradictory effects on lung function and quality of life. Chest 1992;102:1384-91.

101 Gerard K. A review of cost utility studies: assessing their policy-making relevance. University of Aberdeen: Health Economics Research Unit, HERU Discussion Paper 11/91, 1991.

102 Huijsman R, Rutten FFH. The economics of care for the elderty; a research programme. Rotterdam: Erasmus University, iMTA-report no. 91-02, 1991.

103 Gerard K, Mooney G. QALY league tables: handle with care. Hith Econ 1993;2:59-64.

104 Weel $C$ van, Rosser $\mathrm{WW}$. Measuring functional status in family practice. Family Pract 1991;8:394-5.

105 Hunt SM, McEwen J, McKenna SP. Measuring health status: a new tool for clinicians and epidemiologists. J R Coll Gen Pract 1985;35:185-8.

106 McKenna SP, McEwen J, Hunt SM. Changes in the perceived health of patients recovering from fractures. J Public Hlth 1984;98:97-102.

107 Spitz PW, Fries JF. The present and future of comprehensive outcome measures for rheumatic diseases. Clin Rheumatol 1987;6:105-11.

Received 16 Jaruary 1994, accepted 24 November 1994 